\title{
Psychographics: Static or dynamic?
}

Jeong-Yeol Park

Hospitality and Tourism Management

Purdue University

and

SooCheong (Shawn) Jang

Hospitality and Tourism Management

Purdue University

\begin{abstract}
Stanley Plog's psychographics model was introduced in 1967 and has been widely accepted by various researchers and marketing companies. Plog's main point was that travelers' personality characteristics, or psychographics, are determinants of their travel patterns and preferences. The main objective of this study was to verify whether or not Plog's model is flawed by defining travelers in terms of a "static" category. Since satisfaction is generally accepted as an important factor determining revisit intention, this study proposes that allocentric travelers can show a high revisit intention to a destination if they are satisfied. This prediction contrasts Plog's claims that psychographics are static. To test Plog's model, past intention to visit, satisfaction, and revisit intention were compared by one-way ANOVA and Duncan post-hoc test. As a result, the general characteristics of psychocentrics did not differ from the other segments when the level of satisfaction was high. In other words, psychographic segmentation may shift, especially when the level of satisfaction is high. In other words, psychographic segmentation may dynamically shift, especially when the level of satisfaction is high.
\end{abstract}

Keywords: tourism, psychographics, lifestyle, satisfaction, revisit intention.

\section{INTRODUCTION}

Stanley Plog's psychographics model was introduced in 1967 and has been widely accepted by various researchers and marketing companies (Litvin, 2006). Plog's psychographics model was the first model to segment travelers into five different types (i.e. psychocentric, near psychocentric, mid-centric, near allocentric, and allocentric) according to the traveler's personality (Litvin, 2006). Plog's main point was that travelers' personality characteristics, or psychographics, are determinants of their travel patterns and preferences.

However, there are also studies that oppose Plog's (1974, 2001, and 2002) claims. Smith (1990) argued that the allocentric-psychocentric model fails to support the hypothesized association between personality types and destination preferences. Litvin (2006) tested Plog's model by showing that ideal destination and the destination most recently visited differ. Other researchers tried to pinpoint whether personal traits are the only determinants of destination choice. For example, even if a traveler is allocentric in nature, financial or other factors may 
cause him or her to demonstrate mid-centric or near-psychocentric travel patterns (Crossley and Jamieson, 1999). Lowyck, Van Lagenhove, and Bollaert (1993) noted that it may not be possible to place travelers in a "single simple category" since human beings are very complex.

According to Plog (2001), the psychographics segment of an individual cannot be changed from one to another. For example, one general characteristic of being allocentric is a low tendency to revisit the same destination. However, many past studies have identified a correlation between satisfaction and revisit intention in regards to travel destinations as well. Considering the correlation between satisfaction and revisit intention, as well as the psychographics of travelers, suggests an important research question: can an allocentric traveler have high intentions to revisit a destination if he or she is satisfied with the destination? By Plog's definition (1974), a traveler's psychographics would remain unchanged. However, the literature on psychographic profiles implies that a traveler may move from allocentric to psychocentric, depending on his or her experience.

The main objective of this study was to verify whether or not Plog's model is flawed by defining travelers in terms of a "static" category. Since satisfaction is generally accepted as an important factor determining revisit intention, this study proposes that allocentric travelers can show a high revisit intention to a destination if they are satisfied. This prediction contrasts Plog's (1974) claims that psychographics are static. The results of this study provide evidence of whether psychographic segmentation is "static" or "dynamic."

\section{LITERATURE REVIEW}

\subsection{Plog's Psychographics}

Plog's research began in the 1960s as an investigation of why certain travelers did not want to travel by airplane and what kind of people did not want to travel by air (Litvin, 2006). After a series of studies Plog derived personality profiles, which are known as psychographics. Psychographic research has been defined as "quantitative research intended to place consumers on psychological dimensions" (Wells, 1975, p. 207). This type of research has been used to analyze consumers' attitudes, perceptions, needs, interests, opinions, activities, and daily lifestyle (Gladwell, 1990).

Plog's model included five psychographic personality types (i.e. psychocentric, near psychocentric, midcentric, near allocentric, and allocentric). The general characteristics of psychocentrics can be defined as follows (Plog, 2001; Plog, 2002):

- less adventuresome and exploring

- cautious and conservative

- restrictive in spending income

- prefer well-known brands of consumer products

- have a high tendency towards revisit intention once they are satisfied

Allocentrics can be defined as follows (Plog, 2001; Plog, 2002):

- curious about and want to explore

- make decisions easily 
- spend income readily

- chooses new products rather than sticking with popular brands

- seeks new destinations on a continuous basis

The main concept of Plog's psychographic segmentation is that the personality scale helps to explain why destinations rise and fall in popularity, revealing that tourists' personality characteristics are determinants for travel patterns and preferences (Plog, 2001). Psychographics has been recognized as very meaningful and relevant (Shih, 1986) and an important means of providing additional information beyond demographic characteristics (Abbey, 1979). As the model gained recognition, various researches have been done related to psychographics (Mayo, 1975; Ryel and Grasse, 1991). In summary, the research suggests that psychographics affect travel patterns and preferences and are very useful for differentiating between consumer groups (Ryel and Grasse, 1991).

\subsection{Satisfaction and Revisit Intention}

An individual's overall satisfaction with a destination can be regarded as equivalent to a subjective evaluation of all past travel experiences to that destination (Huang and Hsu, 2009). A number of studies have been done on satisfaction and revisit intention. Previous studies have found that tourist satisfaction positively affects revisit intention (Anderson and Sullivan, 1993; Cronin and Taylor, 1992), and people are more likely to revisit a destination if they were satisfied with their travel experience.

\subsection{The proposed Dynamic model}

The uniqueness of this study lies in addressing satisfaction and revisit intention in terms of psychographics. According to the results of various studies, a high correlation has been found between satisfaction and revisit intention (Anderson and Sullivan, 1993). While Plog admitted that there might be a chance of psychographic segments converging, he still insisted the definition itself would remain the same (Plog, 2001).

Considering the vast number of results from previous studies regarding satisfaction and revisit intention, Plog's model may have misclassified or misused the definitions of each segment. The personal traits, or human nature, may remain the same. However, based on the past literature on satisfaction and revision intention, it may be possible for psychographic segments to change or move from one segment to another on the basis of travel experiences. In this respect, this study proposed the hypothesis that travelers' psychographics can change based on a satisfying experience. To test the hypothesis, this study empirically compared psychographic segments in terms of revisit intention at different levels of satisfaction after a spa visit.

\section{METHODOLOGY}

\subsection{Data}

The population for study was composed of travelers visiting Suanbo, a spa town in Korea. Using SPSS 15.0 random sampling function, three spa facilities were selected from an existing 28 facilities. To avoid sample bias, a systematic sampling method was used. Every third 
customer who finished using the spas' facilities was asked to complete a survey. A total of 300 questionnaires were distributed, however 60 questionnaires were not returned, and 31 were eliminated because respondents did not complete the survey. Consequently, the final sample consisted of 209 travelers.

\subsection{Variables}

Respondents were asked to rate two intention variables (i.e. intention to visit before spa visit and the revisit intention) and satisfaction on a 5-point Likert scale. To find out the personal traits related to psychographics, 11 VALS questions were adopted. The last part of the questionnaire was composed of demographic variables (i.e. gender, age, average household income, and years of education).

The purpose of the VALS survey is to identify the VALS type of the person taking the survey. The survey was designed to find out about a person's product ownership, media preferences, hobbies, attitudes, and additional demographics. VALS categorizes the respondent into eight different types; 1) innovators, 2) thinkers, 3) believers, 4) achievers, 5) strivers, 6) experiencers, 7) makers, and 8) survivors. Since VALS is a psychographic system that links demographics and psychological attitudes, VALS has been used by several researchers to analyze psychographic classification (Shih; 1986, Rousseau, 1990; Winters, 1992). Comparing VALS questions with the study by Ahmed (1989), out of 35, 11 questions were selected and used to measure the personal traits of respondents.

\section{RESULTS}

\subsection{Descriptive Statistics of Sample}

Psychographics were assigned according to the mean of lifestyle variables. According to Plog (2002), the proportion of midcentrics was 63\%, the sum of psychocentrics and nearpsychocentrics was $17.94 \%$, and the sum of allocentrics and near-allocentrics was $14.83 \%$. Accordingly, this study assigned proportions for each group based on Plog's earlier definition, but due to the small sample size three psychographic groups were adopted instead of six by combining near-allocentrics and near-psychocentrics into midcentrics.

Table 1. Descriptive Statistics of Samples

\begin{tabular}{ccccccc}
\hline \multirow{2}{*}{ Psychographics } & \multirow{2}{*}{$\mathbf{N}(\%)$} & Male & Female & Age & Income $^{\mathbf{a}}$ & \multirow{2}{*}{ Education $^{\mathbf{b}}$} \\
\hline \hline Psychocentrics & $36(17.2)$ & $16(44.4)$ & $20(55.6)$ & 40.58 & 3.38 & 12.72 \\
Midcentrics & $142(67.9)$ & $76(53.5)$ & $66(46.5)$ & 37.00 & 3.48 & 13.45 \\
Allocentrics & $31(14.8)$ & $18(58.1)$ & $13(41.9)$ & 27.52 & 3.77 & 14.39 \\
\hline Total & $\mathbf{2 0 9}(\mathbf{1 0 0 . 0})$ & $\mathbf{2 0 9}(\mathbf{1 0 0 . 0})$ & $\mathbf{3 6 . 2 1}$ & $\mathbf{3 . 5 1}$ & $\mathbf{1 3 . 4 6}$ \\
\hline
\end{tabular}

a: Monthly household income in Korean currency (million Won)

b: Years of education 


\subsection{Testing the general characteristics of psychographics}

The general characteristics of psychographics were used to test whether the samples were correctly classified. One-way ANOVA was used to test the difference between each psychographics types, age, income, and year of education. A significant difference was noticed in lifestyle variables, age, and years of education. For each lifestyle variable, psychocentrics were found to have the lowest level of general characteristics, but allocentrics were found to have the highest level of general characteristics.

Psychocentrics were found out to have the lowest mean score, to be the oldest, and to have the least years of education among the three groups. However, allocentrics were found to have the highest mean score, were the youngest, and had the highest level of education. Midcentrics were relatively older than allocentrics but not significantly different from psychocentrics. Their level of education was significantly lower than allocentrics, but no different from psychocentrics. Summarizing the descriptive statistics, all three segments were found to have the general characteristics Plog defined.

Table 2. Difference in lifestyle variables among psychographic segments

\begin{tabular}{lcccc}
\hline \multicolumn{1}{c}{ Lifestyle Variables } & Psychocentrics & Midcentrics & Allocentrics & F \\
\hline \hline I like outrageous people and things & 2.42 & 3.18 & 4.10 & $37.83^{* * *}$ \\
I like variety in my life & 2.53 & 3.56 & 4.39 & $53.48^{* * * *}$ \\
I like to learn & 3.00 & 3.44 & 3.97 & $12.37^{* * *}$ \\
I like trying new things & 2.67 & 3.49 & 4.61 & $57.87^{* * *}$ \\
I like to spend some years in a foreign country & 2.33 & 3.52 & 4.74 & $61.83^{* * *}$ \\
I like excitement in life & 2.83 & 3.73 & 4.87 & $55.58^{* * *}$ \\
I like the challenge of doing new things & 2.64 & 3.48 & 4.65 & $71.69^{* * * *}$ \\
I like to learn about things even if they are useless to & 2.72 & 3.28 & 4.23 & $32.67^{* * * *}$ \\
me & 2.53 & 3.20 & 4.06 & $30.91^{* * * *}$ \\
I am looking for a thrill & 2.47 & 3.38 & 4.42 & $65.06^{* * *}$ \\
I like doing new and different things & 2.81 & 3.25 & 4.35 & $27.10^{* * * *}$ \\
\hline I don't like routine life & $\mathbf{2 . 6 3}$ & $\mathbf{3 . 4 1}$ & $\mathbf{4 . 4 0}$ & $\mathbf{2 8 7 . 0 3 ^ { * * * * }}$ \\
\hline \hline Total Mean & & & & \\
\hline
\end{tabular}

$* * *: \mathrm{p}<0.01$ 
Table 3. Difference in demographic variables among psychographic segments

\begin{tabular}{ccccc}
\hline & Psychocentrics & Midcentrics & Allocentrics & F \\
\hline \hline \multirow{2}{*}{ Mean Score } & 2.63 & 3.41 & 4.40 & $287.03^{* * * *}$ \\
& $\left(\mathrm{~L}^{\mathrm{a}}\right)$ & $(\mathrm{M})$ & $(\mathrm{H})$ & \\
Age & 40.58 & 37.00 & 27.52 & $13.69^{* * *}$ \\
& $(\mathrm{H})$ & $(\mathrm{H})$ & 3.77 & 0.35 \\
Income $^{\mathrm{b}}$ & 3.38 & 3.48 & 14.39 & $5.85^{* * *}$ \\
& 12.72 & 13.45 & $(\mathrm{H})$ & \\
\hline Education & $(\mathrm{L})$ & $(\mathrm{L})$ &
\end{tabular}

a: $\mathrm{L}<\mathrm{M}<\mathrm{H}$

b: Monthly household income in Korean currency (million Won)

$* * *: \mathrm{p}<0.01$

\subsection{Changing Revisit Intention}

The main purpose of this study is to find evidence that psychographics can be dynamic by showing that there is no difference in revisit intention between allocentric and psychocentric segments after satisfaction. To test Plog's model, past intention to visit, satisfaction, and revisit intention were compared by one-way ANOVA and Duncan post-hoc test.

Before testing for a change in revisit intention associated with satisfaction, the 'initial' past intention to visit among the three segments was checked. No differences were found. This means that the destination itself was a neutral characteristic that could be attractive to all segments.

Plog's model implies that psychocentrics have the highest revisit intention once satisfied. However, considering satisfaction along with revisit intention, no significant difference was noticed among psychographic segments when the level of satisfaction was higher than four ("satisfied" and "very satisfied"). In other words, those who were allocentric showed the same level of high revisit intention with the spa experience if they were satisfied as those who were psychocentrics.

When the level of satisfaction fell to three ("moderate"), a difference in revisit intention was noticed. There was no significant difference in past intentions to visit, but significant difference in revisit intention was noticed. Psychocentrics showed higher revisit intention than midcentrics and allocentrics did. That is, psychocentrics were found to maintain their general characteristics when the level of satisfaction was relatively low.

Based on the above results, the revisit intentions of satisfied allocentric travelers could not be differentiated from satisfied psychocentric travelers, which diverges from what Plog (1976) suggested. However, unsatisfied allocentrics showed statistically lower revisit intention than unsatisfied psychocentrics, which is consistent with Plog (1976). Supporting our hypothesis, these results provide evidence that at the least the behavior/behavioral intentions of allocentrics can differ from what Plog (1976) originally stated, and perhaps that psychographics are malleable as well. 
Table 5. Difference in past intention to visit and revisit intention considering satisfaction

\begin{tabular}{cccccc}
\hline Satisfaction & Intention & Psychocentrics & Midcentrics & Allocentrics & F \\
\hline \hline Not considered & $\mathrm{PI}^{\mathrm{a}}$ & 3.278 & 2,958 & 2.806 & 1.296 \\
\hline More than & $\mathrm{PI}$ & 3.750 & 3.571 & 3.125 & 1.357 \\
satisfied & $\mathrm{RI}^{\mathrm{b}}$ & 4.250 & 4.014 & 3.875 & 1.161 \\
\hline \multirow{3}{*}{ Moderate } & $\mathrm{PI}$ & 3.000 & 2.467 & 2.388 & 1.612 \\
& $\mathrm{RI}$ & 2.500 & 2.000 & 1.910 & $6.082^{* * * *}$ \\
& & $(\mathrm{H})$ & $(\mathrm{L})$ & $(\mathrm{L})$ & \\
\hline
\end{tabular}

a: PI: Past Intention to Visit; b: RI: Revisit Intention; ***: $\mathrm{p}<0.01$

\section{CONCLUSION}

The Main purpose of this study was to test Plog's model, concentrating on whether psychographic types may be dynamic rather than static. As noted by Plog (2001), psychographics are used to differentiate traveler types and have been widely accepted. However, even he did acknowledge the possibility of the convergence of psychographic segments (Plog, 2001), Plog still insists that psychographics are the major determinants of travelers' travel patterns.

This study tested Plog's model by showing that the general characteristics of psychographic profiles are not fully applicable after a satisfying travel experience. First of all, the destination itself proved to be a neutral destination because there was no difference in past intention to visit. Second, no significant difference in revisit intention was noticed when the level of satisfaction was high. Third, when the level of satisfaction was relatively low, a difference in revisit intention was found between allocentrics and psychocentrics. From a conservative perspective, human nature itself may not change or move, as the initial psychographic typology indicated. However, the general characteristics of psychocentrics did not differ from the other segments when the level of satisfaction was high. In other words, psychographic segmentation may shift, especially when the level of satisfaction is high.

It is undeniable that this study has limitations. Since the data was collected from only one destination it may not be appropriate to generalize the results of this study. Another limitation is related to sample size. While this study introduced a new research direction for a dynamic understanding of psychographics, a great deal of further research exploring the influence of satisfaction on psychographic segmentation is still needed.

\section{REFERENCES}

Abbey, J. (1979) Does life style profiling work? Journal of Travel Research, 18(1), 8-14.

Ahmed, S. A. (1989). Psychological profiles of Sri Lankans versus tourists. Annals of Tourism Research, 16, 345-359. 
Anderson, E. W., and Sullivan, M. W. (1993). The antecedents and consequences of customer satisfaction for firms. Marketing Science, 12, 125-143.

Cronin, J. J., and Taylor, S., A. (1992). Measuring service quality: a reexamination and extension. Journal of Marketing, 56, 55-68.

Crossley, J. C. and Jamieson, L. M. (1999). Introduction to Commercial and Entrepreneurial Recreation. Champaign, IL: Sagamore Publishing.

Gladwell, N. (1990). A psychographic and sociodemographic analysis of state park inn users. Journal of Travel Research, 26, 15-20.

Huang, S. and Hsu, C. H. C. (2009). Effects of travel motivation, past experience, perceived constraint, and attitude on revisit intention. Journal of Travel Research, 48, 1-29.

Litvin, S. W. (2006). Revisiting Plog's model of allocentricity and psychocentricity... one more time. Cornell Hotel and Restaurant Administration Quarterly, 47(3), 245-253.

Lowyck, E., Van Langenhove, L., and Bollaert, L. (1993). Choice and Demand in Tourism, ed. P. Johnson and B. Tomas. London: Mensell Publishing.

Mayo, E. (1975). Tourism and the national park: A psychographic and attitudinal study. Journal of Travel Research, 14(1), 14-17.

Plog, S. C. (1974). Why destination areas rise and fall in popularity. The Cornell Hotel and Restaurant Administration Quarterly, 4, 55-58.

(2001). Why destination areas rise and fall in popularity. Cornell Hotel and Restaurant Administration Quarterly, 42(3), 13 24.

(2002). The power of psychographics and the concept of venturesomeness. Journal of Travel Research, 40, 244-251.

Rousseau, G. G., and Kruger, J. (1990). Testing the value and life-style model (VALS) of psychographic market segmentation. SA Journal of Industrial Psychology, 16(1), 31-37.

Ryel, R. and Grasse, T. (1991). Marketing ecotourism: Attracting the elusive ecotourist. In T. Whelan (Ed.), Nature tourism (pp.164-186). Washington, DC: Island Press.

Shih, D. (1986). VALS as a tool of tourism market research: The Pennsylvania experience. Journal of Travel Research, 24(4), 2-11.

Smith, S. L. J. (1990). A test of Plog's allocentric/psychocentric model: evidence from seven nations. Journal of Travel Research, 28(4), 40-43.

Wells, W. (1975). Psychographics: A critical review. Journal of Marketing Research, 12, 196-213.

Winters, L. C. (1992). International psychographics. Marketing Research, 4, 48-51. 